\title{
The Relationship between Physical Activity, Body Mass Index and Body Composition among Students at a Pre-University Centre in Malaysia.
}

\author{
You $H W^{a}$, Tan $P L^{a}$, Mat Ludin $A F^{b}$ \\ ${ }^{a}$ Pusat GENIUS@Pintar Negara, Universiti Kebangsaan Malaysia, 43600 UKM Bangi, Selangor, Malaysia \\ ${ }^{\mathrm{b}}$ Center for Healthy Ageing and Wellness, H-CARE, Faculty of Health Sciences, Universiti Kebangsaan \\ Malaysia, 50300 Jalan Raja Muda Abd Aziz, Kuala Lumpur, Malaysia.
}

\section{ABSTRACT}

INTRODUCTION: Physical activity is an essential element in our daily life that leads to long-term health benefits. Physical activity refers to movement of the body that requires energy. Body mass index (BMI) indicates a ratio of body weight to squared height, which is a useful health indicator. On the contrary, body composition describes the body by measuring percentages of fat and muscle in human bodies. MATERIALS AND METHODS: This cross-sectional study aimed to determine the relationship between physical activities, BMI and body composition among pre-university students from one of the universities in Selangor, Malaysia. Stratified random sampling was employed to recruit 70 pre-university students into this study. RESULTS: From the study, $50 \%$ of the respondents are categorized as minimally active. In addition, there is significant difference between the physical activity levels of male and female respondents. The relationship between physical activity and BMI indicates a very weak negative correlation. Similarly, the correlation between physical activity and fat mass is a weak negative relationship. Meanwhile, there is a weak positive correlation between physical activity and muscle mass. CONCLUSION: Therefore, it can be concluded that when physical activity increases, BMI and body fat mass will decrease, while muscle mass will increase. Moreover, it was shown that there was a significant relationship between physical activity and body composition.

KEYWORDS: physical activity, body mass index, body fat mass, muscle mass, pre-university students

\section{INTRODUCTION}

Body composition is one of the health related physical fitness. It describes the percentages of fat, muscle, water and bone in the human body. ${ }^{1}$ Excess calories is converted into fat and stored in our body. On the contrary, muscle mass is the predicted weight of muscle in the body. Muscle mass includes the skeletal muscles, smooth muscles and cardiac muscles which act as an engine in consuming energy. When muscle mass increases, the rate of consuming energy (calories) increases, which in turn reduces excess body fat.

Corresponding Author:

Dr. You Huay Woon

Pusat PERMATApintar Negara,

Universiti Kebangsaan Malaysia,

43600 UKM Bangi, Selangor, Malaysia.

No Tel : +60176069458

Email : hwyou@ukm.edu.my
One factor that affects the body composition is physical activity. ${ }^{2}$ Physical activity is defined as the movement of the body produced by skeletal muscle activity resulted in energy expenditure. Activities such as walking, gardening, jogging, climbing stairs or playing soccer are counted as physical activities. According to the International Physical Activities Questionnaire (IPAQ) that commenced in Geneva in 1998, levels of physical activity mainly consists of three categories: Inactive, Minimally Active and HEPA Active. ${ }^{3}$ For health benefits, the intensity of physical activity should be minimally active or HEPA active. ${ }^{4}$

Body Mass Index (BMI) is a referencing tool to determine the standard weight status of a person with their corresponding height. ${ }^{5} \mathrm{BMI}$ can be used to determine the weight categories, and may be used to indicate health and nutritional status. There are four weight categories in the BMI, i.e. underweight, normal weight, overweight and obese. BMI values are 
independent of age and applicable for both males and females. 6

Florido et al. ${ }^{7}$ reported that when physical activities are increased, the chances of having cardiac injury or becoming obese are lessened. People with lower physical activity levels are more likely to be women. ${ }^{7}$ One of the most efficient ways to overcome the prevalence of obesity is to increase the level of physical activity. ${ }^{8,9}$

Being involved in physical activities may also help in maintaining good-looking bodies and promotes physical fitness. ${ }^{10}$ People with sedentary lifestyles are very likely to have greater body fat and BMI compared to people with active lifestyles. ${ }^{11}$ This is because body fat has a negative correlation with total energy expenditure. ${ }^{12}$

Physical activities affect the BMI value and body composition. ${ }^{13-15}$ Physically inactive on the other hand is a risk factor for non-communicable diseases. It has become a global problem. ${ }^{16,17}$ Regardless of the importance of having normal BMI and being physically active are essential, findings from local study are worrying. Mansor et al. ${ }^{18}$ reported more than $30 \%$ of respondents are overweight and obese and majority of them spent about 5 hours a day being inactive. The importance of physical activity is difficult to be promoted, especially among students who have hectic study schedules. This study aimed to determine the relationship between physical activity, BMI and body composition among preuniversity students.

The rest of this article is structured as follows: the methodology to implement in this study is discussed in Section 2, results and discussion are elaborated in Section 3 and finally, Section 4 provides concluding remarks.

\section{MATERIALS AND METHODS}

This cross sectional study was conducted among pre-university students from one of the public universities in Selangor, Malaysia for the academic year 2017/2018. We employed a stratified random sampling method to recruit participants into the study. This particular batch consist of 7 sets of student. We randomly chose 10 students from each set. Inform consents were obtained from each participant prior to this study. Their physical activity level was assessed using a self-administered questionnaire; an IPAQ. Scoring for the IPAQ was done according to the guideline. ${ }^{19}$ The score was later been classified into 3 groups (Table I). Body weight and body composition were assessed using the TANITA Body Composition Analyser. The BMI of each participants was calculated using the following equation:

$$
\mathrm{BMI}=\frac{\operatorname{mass}(k g)}{\operatorname{height}^{2}\left(m^{2}\right)}
$$

The BMI was later been categorised accordingly composes of four categories, which are underweight, normal weight, overweight and obese (Table II).

Table I: Physical Activity Level

\begin{tabular}{ll}
\hline Physical Activity Level & Description \\
\hline Inactive & $\begin{array}{l}\text { Lowest level of physical } \\
\text { activity with less than } 600 \mathrm{MET} \\
\text {-minutes/week }\end{array}$ \\
Minimally Active & $\begin{array}{l}\text { Achieving a minimum of at } \\
\text { least } 600 \mathrm{MET} \text {-minutes/week }\end{array}$ \\
HEPA Active & $\begin{array}{l}\text { Achieving a minimum of at } \\
\text { least } 3000 \mathrm{MET} \text {-minutes/week. }\end{array}$ \\
\hline
\end{tabular}

Table II: Standard Weight Status Categories Based on BMI Value

\begin{tabular}{ll}
\hline BMI Value & Standard weight status categories \\
\hline$<18.5$ & Underweight \\
$18.5-24.9$ & Normal Weight \\
$25.0-29.9$ & Overweight \\
$>30.0$ & Obese \\
\hline
\end{tabular}

Source: American Cancer Society, 2016

\section{RESULTS AND DISCUSSION}

Out of the 70 participants, 42 were females. The finding shows that $52.9 \%$ was of normal weight. Nearly $26 \%$ of participants categorised as either overweight or obese, while nearly $21.4 \%$ of the respondents fell under the underweight category (see Table III). 
Table III: BMI, Body Composition and Physical Activity Level among 70 participants

\begin{tabular}{|c|c|c|c|c|}
\hline & $\begin{array}{l}\text { Overall } \\
\mathrm{N}=70\end{array}$ & $\begin{array}{l}\text { Female } \\
\mathrm{n}=42\end{array}$ & $\begin{array}{l}\text { Male } \\
n=28\end{array}$ & Significant level \\
\hline BMI & $22.38 \pm 1.04$ & $22.32 \pm 1.26$ & $22.47 \pm 1.90$ & .000 \\
\hline Underweight & $15(21.4 \%)$ & $8(19.1 \%)$ & $7(25.0 \%)$ & \\
\hline Normal & 37 (52.9\%) & $24(57.1 \%)$ & $13(46.4 \%)$ & \\
\hline Overweight & $15(21.4 \%)$ & $9(21.4 \%)$ & $6(21.4 \%)$ & \\
\hline Obese & $3(4.3 \%)$ & $1(2.4 \%)$ & $2(7.2 \%)$ & \\
\hline \multicolumn{5}{|l|}{ Body Composition } \\
\hline Fat mass $(\mathbf{k g})$ & $14.41 \pm 1.95$ & $17.16 \pm 2.24$ & $10.28 \pm 3.09$ & .000 \\
\hline Muscle mass (kg) & $42.74 \pm 2.22$ & $36.87 \pm 1.41$ & $51.54 \pm 2.94$ & .000 \\
\hline Physical Activity Level & $2415.61 \pm 608.89$ & $1826.49 \pm 455.93$ & $3299.29 \pm 1346.85$ & .000 \\
\hline Inactive & $12(17.1 \%)$ & $7(16.7 \%)$ & $5(17.9 \%)$ & \\
\hline Minimally active & $35(50 \%)$ & $25(59.5 \%)$ & $10(35.7 \%)$ & \\
\hline HEPA active & $23(32.9 \%)$ & $10(23.8 \%)$ & $13(46.4 \%)$ & \\
\hline
\end{tabular}

Half of the participants is categorised as minimally active, $33 \%$ are HEPA active while $17 \%$ is categorised as inactive. This is a positive indication in which more than half of the pre-university students are involved in moderate- and vigorous-intensity physical activities.

Moreover, it is evident that females are less involved in vigorous activity than males, i.e. $23.8 \%$ vs $46.4 \%$. To further determine whether there is a significance difference in physical activity between gender groups, it shows that there is a significant difference in physical activity levels between the male and female with $p$-value $<0.05$. This supports the findings that among the respondents, there is a difference between genders in terms of physical activity levels.

To investigate the relationship between physical activity, BMI and body composition, the normality of all the data (physical activity, BMI, fat mass and muscle mass) are tested using the KolmogorovSmirnov test. This test is used when the sample size is more than 50 . The results indicate that the data of all the four variables are not normally distributed (Sig. <0.05). Hence, non-parametric correlations are used to analyse the collected data.

To examine whether there is any significant relationship between the physical activity and BMI, the Spearman's Rho correlation coefficient was employed here. Table IV shows that there was a very weak negative correlation between physical activity and BMI $(r=-0.084)$. This correlation coefficient is illustrated in the form of the scatter plot in Figure 1. This indicates that when physical activity increases, the value of BMI decreases. This is similar to a study done by Riddifor-Harland et al. ${ }^{8}$, where the risk of being overweight was found to decrease with increased levels of physical activity. From the results obtained, it can be said that physical activity has an impact on the participants' BMIs. To maintain a BMI value within the normal range, one should be more involved in physical activity. However, there was no significant relationship between the physical activity and BMI with $p$-value $=0.246>0.05$. Hence, there is insufficient evidence to suggest that a very weak negative correlation also exists in the population.

Table IV: Correlation analysis between physical activity level, BMI, fat mass and muscle mass

\begin{tabular}{ll}
\hline & $r$ \\
\hline PA vs BMI & -.084 \\
PA vs FatMass & -.225 \\
PA vs Muscle Mass & .225 \\
\hline
\end{tabular}

PA: physical activity; BMI: Body Mass Index.

Body fat mass is believed to be another factor affected by physical activity among the preuniversity students. Clearly, the relationship between physical activity and fat mass is a weak negative linear relationship, i.e. $r=-0.225$ (refer to Table IV). The relationship was significant with $p$ - 


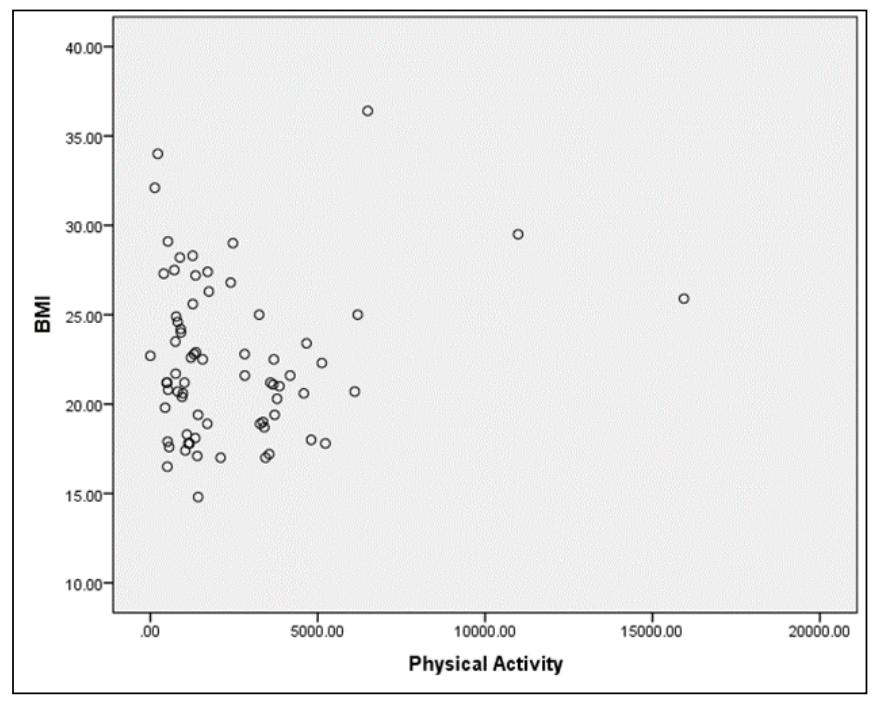

Figure 1: Scatter Plot of BMI against Physical Activity

value $<0.05$ and this means that when physical activity increases, body fat mass decreases. It can be viewed that physical activity is a useful activity to lower the level of unwanted fat, a finding that is in accordance to Knowler. ${ }^{20}$ Thus, physical activity is highly encouraged among the respondents, who are teenagers of 18 and 19 years old. This is because the issues of being overweight and being obese are prevalent among adolescents nowadays. Therefore, excess body fat which will lead to the problem of being overweight and being obese should be reduced. This can be achieved by promoting healthy lifestyles. This correlation pattern can be seen in the scatter plot in Figure 2.

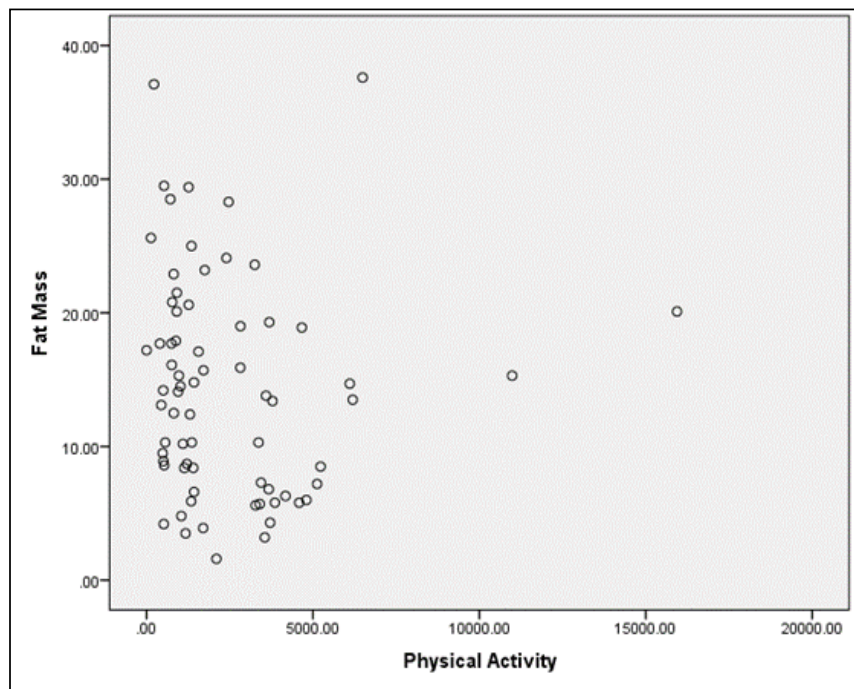

Figure 2: Scatter Plot of Fat Mass against Physical Activity

Muscle mass is also a part of the body composition which is an important discussion point in this study. From the results obtained in Table IV, the correlation between physical activity and muscle mass is a weak positive linear relationship of $r=$
0.225. This shows that when physical activity increases, body muscle mass also increases as visually represented in the scatter plot in Figure 3. This can be related to the findings stating active involvement in physical activity may also help in maintaining well-looking bodies. ${ }^{10}$ Moreover, it can be derived that there is a significant relationship between physical activity and muscle mass with $p$ value $<0.05$. Therefore, this suggests that a weak positive linear relationship between physical activity and body muscle mass is also existent in the population. According to Aszrin et al. ${ }^{21}$, students are much more likely to improve their academic performance with good health conditions.

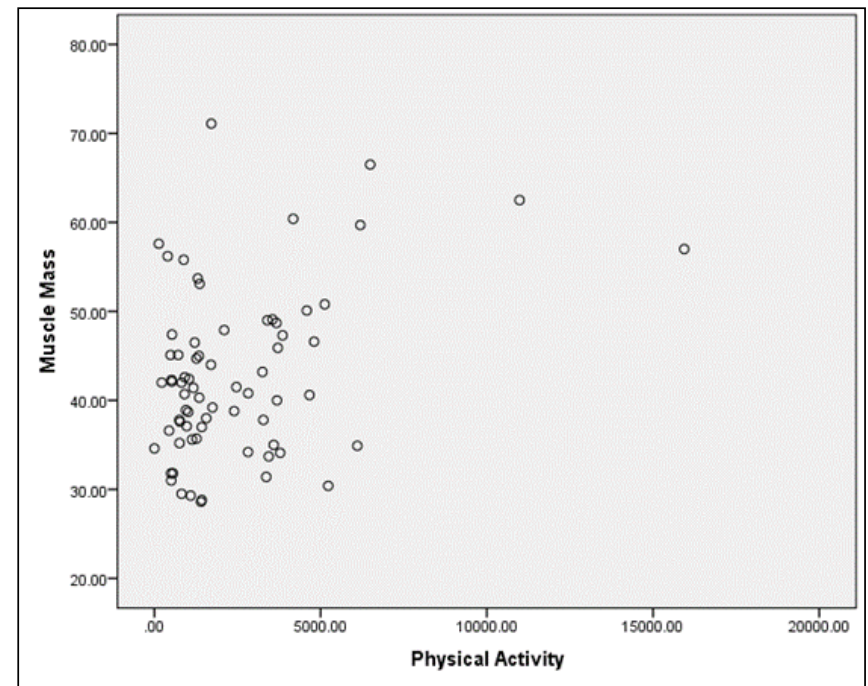

Figure 3: Scatter Plot of Muscle Mass against Physical Activity

\section{CONCLUSION}

From this study, physical activity has a weak negative and weak positive correlation with fat mass and muscle mass, respectively. In addition, there was a very weak negative correlation between physical activity and BMI. Nevertheless, it was demonstrated that there is a significant relationship between physical activity and body composition, i.e. fast mass and muscle mass. Meanwhile, physical activity has no significant relationship with BMI. Hence, we can suggest that there is sufficient evidence showing a correlation between physical activity and body composition in the population. This results obtained is in accordance to past research.

It can therefore be concluded that being actively involved in physical activity will help in increasing physical fitness as well as promoting a healthy lifestyle. This is extremely important as a healthy 
body is required for good academic performance. Awareness of the importance of physical activity among students should be increased so that it will lead to positive impacts in decreasing the phenomenon of obesity. In light of this, the need to incorporate active lifestyle in curriculum development to counter the sedentary and obesity related problems is crucial. Future research can be conducted using a bigger sample in order to generalise the results. Furthermore, other factors, such as diet, can be included for a comparative study on BMI and body composition.

\section{REFERENCES}

1. The Oxford Companion to the Body (2001). Composition of the Body. Available at http:// www.encyclopedia.com/medicine/ encyclopedias-almanacs-transcripts-and-maps/ composition-body. Accessed February 16, 2018.

2. Yoshioka M, Ayabe M, Yahiro T, Higuchi H, Higaki $\mathrm{Y}$, et al. Long-period accelerometer monitoring shows the role of physical activity in overweight and obesity. International Journal of Obesity 2005; 29(5), 502-508. https://doi.org/10.1038/ sj.ijo.0802891

3. IPAQ Group. Guidelines for Data Processing and Analysis of the International Physical Activity Questionnaire (IPAQ): Short form. [Internet]. The Group;April 2004 [cited 2018 Dec].

Available from https://www.researchgate.net/ profile/Malgorzata_Wasilewska/post/

How_to_measurement_physical_activity_and_fo od_frequency_questionnaire_among_children_an d_adolescents/ attachment/59d642a779197b807799e502/AS\% 3A439636968382468\%401481829029244/ download/ Manual+scoring_short_ipaq_april04.pdf

4. Haskell WL, Lee IM, Pate RR, Powell KE, Blair SN, et al. Physical activity and public health: Updated recommendation for adults from the American College of Sports Medicine and the American Heart Association. Medicine and Science in Sports and Exercise 2007; 39(8), 14231434. DOI: $10.1249 / \mathrm{mss} .0 \mathrm{~b} 013 \mathrm{e} 3180616 \mathrm{~b} 27$

5. Medical News Today. (2016). BMI (Body Mass Index). Available at http:// www.medicalnewstoday.com/info/obesity/what -is-bmi.php\#what_is_bmi. Accessed November 27, 2017.
6. Jamani NA, Said AH, Aziz KHA, Rahman MAA. Body weight perception versus body weight status: how good is the agreement? Medical Research Symposium 2018, The International Medical Journal Malaysia 2018, 17(suppl 1).

7. Florido R, Ndumele CE, Kwak L, Pang Y, Matsushita K, et al. Physical Activity, Obesity, and Subclinical Myocardial Damage, JACC Heart Failure 2017; 5(5), 377-384. https:// doi.org/10.1016/j.jchf.2017.02.002

8. Riddiford-Harland DL, Steele JR, Cliff DP, Okely AD, Morgan PJ, Baur LA. Does participation in a physical activity program impact upon the feet of overweight and obese children? Journal of Science and Medicine in Sport 2016; 19(1), 5155. https://doi.org/10.1016/

j.jsams.2014.11.008

9. Graff $M$, Richardson $A S$, Young KL, Mazul AL, Highland $\mathrm{H}$, et al. (2016). The interaction between physical activity and obesity gene variants in association with BMI: Does the obesogenic environment matter? Health and Place 2016; 42, 159-165. https:// doi.org/10.1016/j.healthplace.2016.09.003

10. Muñoz-Vera T, Sañudo B, del Pozo-Cruz B, del Pozo-Cruz J, Lopez-Lluch G, Sánchez-Oliver AJ. Influence of the level of physical activity on physical fitness, lipid profile and health outcomes in overweight/obese adults with similar nutritional status. Science \& Sports 2017; 32(5), 278-285. https://doi.org/10.1016/ j.scispo.2016.05.006

11. Hruby A, Hu FB. The Epidemiology of Obesity: A Big Picture. Pharmacoeconomics 2015; 33(7), 673-689. Doi: 10.1007/s40273-014-0243-x.

12. Fonseca DC, Sala P, Ferreira BAM, Reis J, Torrinhas RS, Bendavid I, Waitzberg DL. Body weight control and energy expenditure. Clinical Nutrition Experimental 2018; 20, 55-59. https://doi.org/10.1016/j.yclnex.2018.04.001

13. Asp M, Simonsson B, Larm P, Molarius A. Physical mobility, physical activity, and obesity among elderly: findings from a large population -based Swedish survey. Public Health 2017; 147, 84-91. https://doi.org/10.1016/ j.puhe.2017.01.032

14. Bradbury KE, Guo W, Cairns BJ, Armstrong MEG, Key TJ. Association between physical activity and body fat percentage, with adjustment for BMI: a large cross-sectional analysis of UK Biobank. BMJ Open 2017; 7(3), e011843. DOI: 10.1136/bmjopen-2016-011843 
15. Lakoski SG, Barlow CE, Farrell SW, Berry JD, Morrow JR, Haskell WL. Impact of body mass index, physical activity, and other clinical factors on cardiorespiratory fitness (from the Cooper Center longitudinal study). The American Journal of Cardiology 2011; 108(1), 34 -39. doi: 10.1016/j.amjcard.2011.02.338. Epub 2011 Apr 27.

16. Blair SN. Physical inactivity: the biggest public health problem of the 21st century. British Journal of Sports Medicine 2009; 43(1), 1-2.

17. Kohl HW, Craig DL, Lambert EV, Inoue $S$, Alkandari JR, Leetongin G, Kahlmeier S. The pandemic of physical inactivity: global action for public health. The Lancet 2012; 380(9838), 294-305.

18. Mansor AA, Abdullah H, Azman A. Sedentary Lifestyle and Body Weight Status among Youth at Public Secondary Schools in Selangor. International Journal of Academic Research in Business and Social Sciences 2017; 7(8), 652659.

19. Craig $C L$, Marshall AL, Sjöström M, Bauman AE, Booth ML, et al. International Physical Activity Questionnaire: 12 country reliability and validity. Medicine and Science in Sports and Exercise 2003; 35(8), 1381-1395.

20. Knowler WC. Reduction in the incidence of Type 2 diabetes with lifestyle intervention or metformin. The New England Journal of Medicine 2002; 346, 393-403. DOI: 10.1056/ NEJMoa012512

21. Aszrin A, Azarisman SM, Jamaluddin RA, Tariq RA, Noriah NM. Prehypertensive state, mild hypertension, metabolic syndrome and cardiovascular risk factors among young adults in rural Malaysia. The International Medical Journal Malaysia 2018; 17(1), 47-54. 
